\title{
Surgical care for the direct and indirect victims of violence in the eastern Democratic Republic of Congo
}

\author{
Kathryn Chu*1,2, Philippe Havet ${ }^{3}$, Nathan Ford 1,4 and Miguel Trelles 5
}

\begin{abstract}
Background: The provision of surgical assistance in conflict is often associated with care for victims of violence. However, there is an increasing appreciation that surgical care is needed for non-traumatic morbidities. In this paper we report on surgical interventions carried out by Médecins sans Frontières in Masisi, North Kivu, Democratic Republic of Congo to contribute to the scarce evidence base on surgical needs in conflict.

Methods: We analysed data on all surgical interventions done at Masisi district hospital between September 2007 and December 2009. Types of interventions are described, and logistic regression used to model associations with violence-related injury.

Results: 2869 operations were performed on 2441 patients. Obstetric emergencies accounted for over half $(675,57 \%)$ of all surgical pathology and infections for another quarter $(160,14 \%)$. Trauma-related injuries accounted for only one quarter $(681,24 \%)$ of all interventions; among these, $363(13 \%)$ were violence-related. Male gender (adjusted odds ratio $(A O R)=20.0, p<0.001$ ), military status $(A O R=4.1, p<0.001)$, and age less than 20 years ( $A O R=2.1, p<0.001$ ) were associated with violence-related injury. Immediate peri-operative mortality was $0.2 \%$.

Conclusions: In this study, most surgical interventions were unrelated to violent trauma and rather reflected the general surgical needs of a low-income tropical country. Programs in conflict zones in low-income countries need to be prepared to treat both the war-wounded and non-trauma related life-threatening surgical needs of the general population. Given the limited surgical workforce in these areas, training of local staff and task shifting is recommended to support broad availability of essential surgical care. Further studies into the surgical needs of the population are warranted, including population-based surveys, to improve program planning and resource allocation and the effectiveness of the humanitarian response.
\end{abstract}

\section{Background}

The provision of surgical assistance in conflict is often associated with care for victims of violence. However, there is an increasing appreciation that surgical care is needed for non-traumatic morbidities [1]. Armed conflict often occurs in low-income countries where fragile health care systems are rapidly overwhelmed during periods of violence and associated population displacement. In such situations, the population becomes even more vulnerable to threats such as poor hygiene, malnutrition, infectious diseases, rape, and poor antenatal care [2].

* Correspondence: kathryn.chu@joburg.msf.org

${ }^{1}$ Médecins sans Frontières, 49 Jorrisen St, Braamfontein 2017, Johannesburg, South Africa

Full list of author information is available at the end of the article
Infections and obstetric emergencies in particular contribute to substantial mortality in these settings and surgical interventions can make an important contribution to reducing death and disability [3].

An accurate understanding of the surgical needs of populations in conflict is therefore important for program planning and resource allocation. Program audits for Médecins sans Frontières (MSF) operations during 2008 found that only $30 \%$ of surgical interventions were due to violence-related injuries; the majority of interventions were for obstetric emergencies and accidental trauma [1]. In this paper we report on surgical interventions carried out by MSF in a zone of active conflict in 
Masisi, North Kivu, Democratic Republic of Congo, and describe risk factors for violence-related injury.

\section{Methods}

\section{Setting}

The Democratic Republic of Congo (DRC) is one of the poorest countries in the world with a per capita GDP of $\$ 300$ [4]. North Kivu, located in Eastern DRC, has been afflicted by conflict since the Rwandan genocide in 1994 which resulted in millions of refugees fleeing into the region. Its close proximity to Uganda and Rwanda also make it vulnerable to incursions by armed groups in these countries. There are various government and rebel factions, but the main conflict is between the DRC military and two militia groups, the Hutu-based Democratic Forces for the Liberation of Rwanda and (the now defunct) National Congress for the Defense of the People (CNDP).

MSF has been in North Kivu since 1992, providing medical services to the displaced and host populations. The estimated 1.4 million internally displaced persons who live in North Kivu make up almost half $(47 \%)$ of the total population [5]. Life expectancy is 46 years [6] and leading causes of death are malaria, diarrhea, respiratory infections, tuberculosis, and neonatal deaths [7]. The terrain is mountainous and poor roads mean the area is only accessible by all terrain vehicles and motorbikes for most of the year.

On August 27, 2007, the CNDP attacked the village of Masisi, located $85 \mathrm{~km}$ from Goma, the capital of North Kivu. Heavy fighting lasted for four days, with small skirmishes continuing for several weeks. Tens of thousands of new IDPs were estimated to have fled the area and while the number of casualties was not reported, similar waves of violence in the DRC are known to have resulted in high civilian mortality [8]. In response, MSF established surgical services in Masisi district hospital to treat the war wounded.

Masisi district has 30 primary health clinics, although many are non-functional due to lack of human resources or essential supplies. The catchment population is difficult to establish because of continuous population displacement but is estimated to be around 306,000 people. Masisi district hospital was established in the late 1960s as the referral hospital for the district. After the August 2007 attacks in Masisi, the hospital was practically abandoned as staff and patients fled to safer areas. Continued fighting has occurred over the past two years with waves of increased violence. MSF began the provision of emergency surgical services in September 2007 by renovating the operating theatre, sterilization unit, and providing surgeons and anesthesiologists. Surgical care is provided by an MSF surgeon with the assistance of Congolese government doctors, while anesthestic services are provided by an MSF anesthesiologist and a Congolese nurse-anesthetist. Over time MSF has expanded support to cover all inpatient services including maternity, pediatrics, and internal medicine, as well as laboratory services and the emergency room. Currently there are 32 surgical beds in the 175-bed hospital. MSF is responsible for all medication and supplies and provides services free of charge to patients.

\section{Data Sources}

For this analysis, we defined surgical interventions as all procedures that required anesthesia and were performed in the operating room. The period of analysis was from September 2007 to December 2009. The following data were prospectively collected using Excel: age, gender, military status, and American Society of Anesthesiology (ASA) physical status classification as well as data on surgical pathology, procedure type, blood transfusions, and operative mortality. Surgical pathology was grouped into the following categories: obstetric emergencies, infection, neoplasm, accidental injury, violence-related injury, and other.

\section{Statistical analysis}

Baseline characteristics were described using medians and interquartile ranges (IQRs) for continuous variables and counts and percentages for categorical data. Associations with violence-related injury were explored using using logistic regression. Variables considered in the analysis included age, gender, military status, ASA classification, and blood transfusions. Factors with a $\mathrm{p}<0.1$ on univariate analysis were included in a multivariate model. All tests and confidence intervals were considered to be significant at a $\mathrm{p} \leq 0.05$. All analyses were performed using STATA 10 (College Station, TX, USA).

\section{Results}

From September 2007 to December 2009, 2869 operations were performed on 2441 patients (15\% re-interventions). The majority $(1855,76 \%)$ were female. Median age was 24 (interquartile range 18-31); 152 (6\%) were under 5 years of age. Sixty-one patients (3\%) were in the military.

$1263(44 \%)$ procedures were performed under spinal anesthesia; 1263 (44\%) under general anesthesia without intubation, and only 115 (4\%) under general anesthesia with intubation. Immediate peri-operative mortality was $0.2 \%$ (20); however, in-hospital mortality was unknown.

\section{Surgical Pathology}

We found that obstetric emergencies accounted for over half $(1463,51 \%)$ of all surgical pathologies, and infections for another quarter $(498,17 \%)$. Trauma-related injuries accounted for only one quarter $(681,24 \%)$ of all interventions; among these, 363 (13\%) were violence-related (Table 1). The proportion of violence-related cases varied 
Table 1: Types of Surgical Pathology

\begin{tabular}{lcc}
\hline & $\mathbf{N}$ & $\mathbf{( \% )}$ \\
\hline Obstetrical Emergencies & 1463 & $(51)$ \\
Infections & 498 & $(17)$ \\
Violence-related Injuries & 363 & $(13)$ \\
Accidental Injuries & 318 & $(11)$ \\
Other* & 142 & $(5)$ \\
Neoplasms & 82 & $(3)$ \\
& & \\
\hline${ }^{*}$ Congenital, latrogenic, Vascular, Other Pathology &
\end{tabular}

from $0-56 \%$, with peaks occurring during major clashes (Figure 1). Gunshot wounds accounted for 94\% (341) of violent injuries (Table 2). The most common non violence-related injuries were burns and falls. The most common procedure for trauma was wound debridement while the most common non-trauma-related procedure was Cesarean section (Table 3).

\section{Associations with violence-related injury}

We assessed risk factors for violence-related injury using a multivariate model that included sex, age, military status, ASA classification, and the provision of blood transfusions. Among these, the following were found to be
Table 2: Causes of Violent Injury

\begin{tabular}{lrr}
\hline & N & (\%) \\
\hline Gunshot Wound & 341 & $(94)$ \\
Knife & 13 & $(4)$ \\
Torture & 5 & $(1)$ \\
Rape & 3 & $(1)$ \\
Missile & 1 & $(0)$ \\
& & \\
\hline Total & 363 & $(100)$ \\
\hline
\end{tabular}

statistically significantly associated with violence-related injury: male gender (adjusted odds ratio $(A O R)=19.2, p$ $<0.001)$, military status (AOR $=4.1, \mathrm{p}<0.001)$, and age less than 20 years $(\mathrm{AOR}=2.1, \mathrm{p}<0.001)($ Table 4$)$.

\section{Conclusions}

This is among the few studies to describe the typology of emergency surgical care in a conflict zone. We found that in this war-ravaged area of Eastern DRC most surgical interventions were unrelated to violent trauma but rather reflected the general surgical needs of a low-income tropical country. Most of the emergency procedures performed were similar to those performed in hospitals in low-income countries not in conflict $[9,10]$. The prevention of maternal and fetal mortality was the most com-

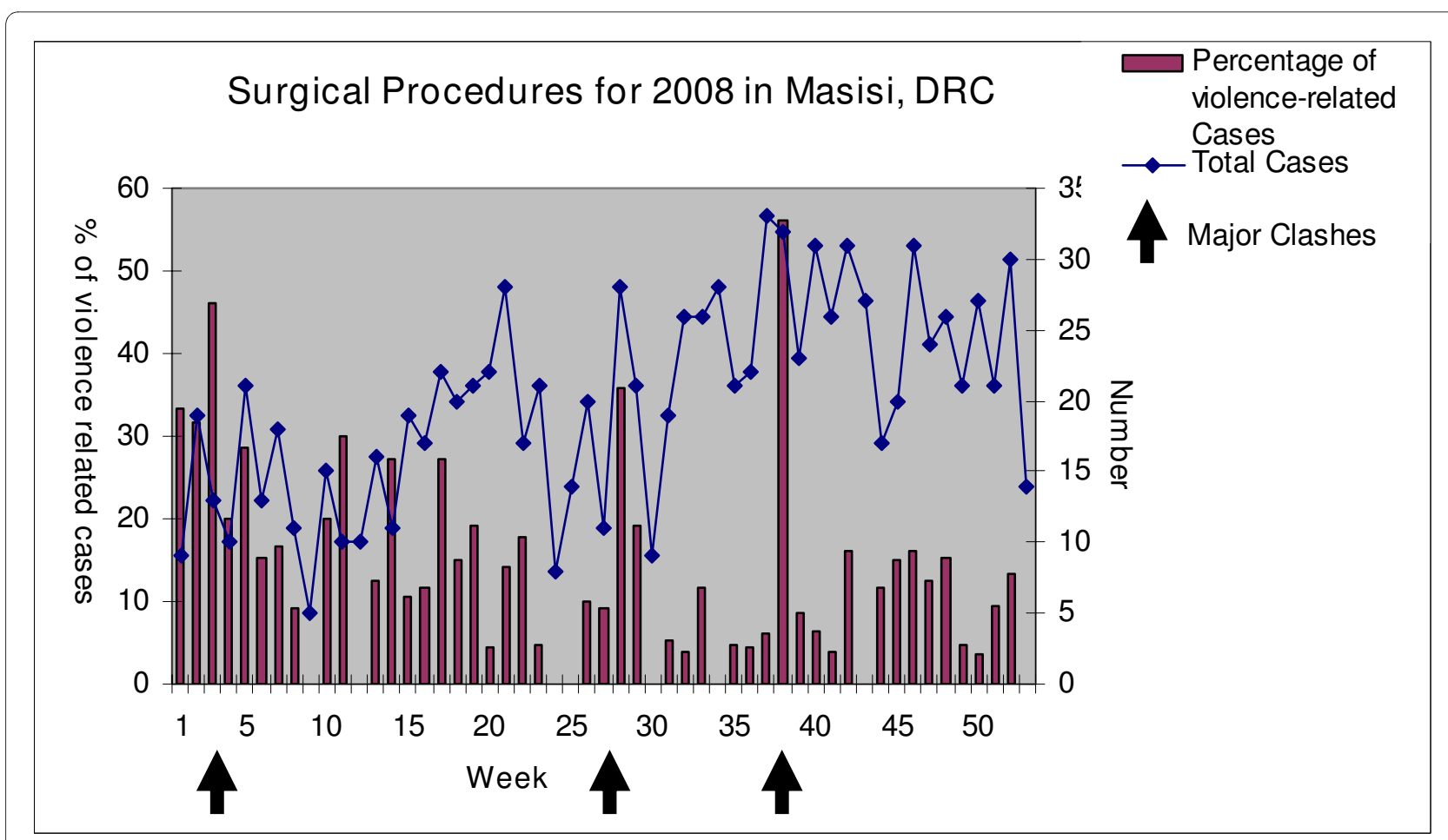

Figure 1 Surgical procedures for 2008 in Masisi, DRC 
Table 3: Trauma and Non-Trauma Related Interventions

\begin{tabular}{|c|c|c|c|c|c|}
\hline Trauma & $\mathbf{N}$ & (\%) & Non-Trauma & $\mathbf{N}$ & $(\%)$ \\
\hline Wound Debridement & 206 & $(30)$ & Cesarean section & 1304 & $(60)$ \\
\hline Dressing Changes under Sedation & 184 & (27) & Suturing, I and D, Circumcision & 237 & (11) \\
\hline Suturing, Incision and Drainage & 126 & (19) & Tubal ligation/Dilation and curretage & 113 & $(5)$ \\
\hline Fracture Reductions & 64 & $(9)$ & Dressing Changes under Sedation & 112 & (5) \\
\hline Abdominal Surgery/Bowel Resection & 21 & (3) & Abdominal Surgery* & 97 & (4) \\
\hline Amputations & 20 & (3) & Wound Debridments & 94 & (4) \\
\hline Skin Grafts & 17 & $(2)$ & Minor Surgery** & 81 & (4) \\
\hline Other & 43 & (6) & Other & 76 & (3) \\
\hline Total & 681 & (100) & Total & 2188 & $(100)$ \\
\hline
\end{tabular}

mon reason for emergency surgery in the Masisi program. Like many populations who suffer a general lack of access to primary health care, this population suffered from accidents, infections, and late-stage neoplastic infections.

These findings are consistent with program audits from other conflict zones in resource-limited settings. A retrospective review of surgical services of Médecins Sans Frontières in six conflict-settings in both Africa (Chad, Somalia, South Sudan, Democratic Republic of Congo, and Central African Republic) and South Asia (Pakistan) found that only $22 \%$ of surgical interventions were due to violent injury, while obstetric emergencies accounted for almost a third (30\%) of interventions and accidental injury and infections another third [1].

Male soldiers younger than 20 years of age were more likely to present with violent trauma. While those patients suffering from violent trauma only accounted for $13 \%$ of the surgical cases, they needed special support such as long-term rehabilitation and psychological counseling. Hospitals in war zones should plan for these needs.

Our study demonstrated that while this project had fully trained surgeons and anesthesiologists, most of the procedures performed were basic. This was in part due to the limitations of the equipment and the lack of post-

Table 4: Associations with Violence-related Injury

\begin{tabular}{|c|c|c|c|c|c|c|}
\hline & \multicolumn{3}{|c|}{ Univariate } & \multicolumn{3}{|c|}{ Multivariate } \\
\hline & OR & $95 \% \mathrm{Cl}$ & $\mathbf{P}$ & OR & $95 \% \mathrm{Cl}$ & $\mathbf{P}$ \\
\hline Female & 1.0 & & & & & \\
\hline Male & 20.0 & $(14.0-28.6)$ & $<0.001$ & & $19.2(13.1-28.1)$ & $<0.001$ \\
\hline Age $\geq 20$ years & 1.0 & & & & & \\
\hline Age $<20$ years & 1.4 & $(1.0-2.0)$ & 0.051 & 2.1 & $(1.5-3.0)$ & $<0.001$ \\
\hline Civillian & 1.0 & & & & & \\
\hline Military & 23.4 & $(13.5-40.6)$ & $<0.001$ & 4.1 & $(2.3-7.4)$ & $<0.001$ \\
\hline ASA 1-2 & 1.0 & & & & & \\
\hline ASA 3-5 & 2.6 & $(1.5-4.4)$ & $<0.001$ & 1.5 & $(0.8-2.8)$ & 0.221 \\
\hline No blood transfusion & 1.0 & & & & & \\
\hline Blood transfusion & 2.2 & $(1.0-5.0)$ & 0.063 & 2.8 & $(0.9-8.5)$ & 0.068 \\
\hline
\end{tabular}

ASA, American Society of Anesthesiologists physical status classification system 
operative intensive care. Also, there was likely to be a selection bias against complex trauma, as patients with severe head or chest trauma likely never made it to the hospital as pre-hospital transport took hours to days. Nevertheless, this finding is important as it indicates that most procedures can be performed by general doctors or non-physician clinicians with surgical skills. For example, it has been shown that the most common surgical intervention, emergency obstetrical care, can with adequate training and supervision be performed safely performed by non-doctors [11-13]. In low-income settings such as Niger, Malawi, and Mozambique, surgical task-shifting has resulted in an increased provision in essential surgical services $[14,15]$. Similarly, most of these procedures were safely performed with spinal anesthesia and ketamine (general anesthesia without intubation) which are safer types of anesthesia to administer for nurse-anesthetists or anesthesia providers that are informally trained.

The potential for non-surgeons to manage a substantial proportion of surgical needs in resource-limited conflict areas is an important consideration given the lack of local surgeons in resource-limited settings [16] and the danger posed to expatriate surgeons (in particular, the higher risk of kidnapping in certain contexts). In Somalia, where MSF expatriate surgeons are not allowed due to insecurity, all surgical procedures are performed by non-surgeons; operative mortality is $<1 \%$. Studies from other settings demonstrate that the training of general doctors with surgical skills and nurse anesthetists is possible, even in a conflict zone $[16,17]$.

This study has certain limitations. The reported numbers of war-wounded were often higher than the number of victims treated at Masisi district hospital, which was the only health care facility providing surgical care in this community. While some likely died prior to arriving at the hospital from severe injuries, others may not have sought care. This study did not measure reasons for service uptake. While all care was free, there may have been other barriers to accessing care including transportation, insecurity, and other family responsibilities. Civilians and soldiers from both sides of the conflict were treated confidentially and respectfully by hospital staff; however, regional and tribal differences between staff and patients may have prevented some patients from seeking care. Special attention to improve access to care for the warwounded and IDPs is needed.

Collecting data in conflict settings is challenging, but not impossible [18]. Our study was limited by our data collection methods. While our coding system captured broad categories of surgical pathology, it was limited in documenting types of operations. The coding system did not distinguish between some minor surgeries such as herniorraphy, hydrocele repair, and hemorrhoid surgery or wound suturing, incision and drainage of abscesses, and circumcision. Knowing the exact cause of many diseases without radiology or pathology services was also difficult. We did not have long-term follow-up of patients nor did we track surgical site infection. While this study described the burden of essential surgical disease in a conflict zone, it could not determine the burden of elective surgical disease. Even though many patients with elective surgical disease were evaluated at the hospital, this was unlikely representative of all the type of surgical disease in the community. Population based studies are needed to estimate the unmet burden of elective surgical disease.

In conclusion, programs in conflict zones in lowincome countries need to be prepared to treat both the war-wounded and non-trauma related life-threatening surgical needs of the general population. While military patients have a greater relative risk of violence-related injuries, civilians still make up the majority of violenceaffected cases in terms of absolute numbers. Training of local staff and task-shifting is essential to ensure that surgical services will be provided when conditions become too dangerous for expatriate surgeons to work in the area. Further studies into the surgical needs of the population are warranted, including population-based surveys, to improve program planning and resource allocation and ultimately the effectiveness of the humanitarian response.

\section{Competing interests}

The authors declare that they have no competing interests.

\section{Authors' contributions}

$\mathrm{KC}$, NF, and MT were responsible for the overall concept and design. KC and MT contributed to the data collection and analysis. KC, NF, and MT contributed to intellectual content, and writing of the paper. $\mathrm{KC}$ wrote the first draft of the paper. All authors reviewed and approved the final version of the paper.

\section{Acknowledgements}

The authors would like to thank the MSF field team in Masisi and the staff from Masisi district hospital for their excellent work and dedication to their patients.

\section{Author Details}

1Médecins sans Frontières, 49 Jorrisen St, Braamfontein 2017, Johannesburg, South Africa, 2 Departments of Surgery and International Health, Johns Hopkins University, Baltimore, MD, USA, ${ }^{3}$ Médecins sans Frontières, Masisi, Democratic Republic of Congo, ${ }^{4}$ Faculty of Health Sciences, Simon Fraser University, Vancouver, Canada and 5 Médecins sans Frontières, rue Dupré 94, 1090 Brussels, Belgium

Received: 24 February 2010 Accepted: 14 April 2010

Published: 14 April 2010

References

1. Chu K, Trelles M, Ford N: Rethinking surgical care in conflict. Lancet 375:262-263.

2. Sidel VW, Levy BS: The health impact of war. Int $\mathrm{J}$ Inj Contr Saf Promot 2008, 15:189-195.

3. Ozgediz D, Riviello R: The "Other" Neglected Diseases in Global Public Health: Surgical Conditions in Sub-Saharan Africa. PLoS Med 2008, 5:e121.

4. Department US. Background Note: Democratic Republic of the Congo. [http://www.state.gov/r/pa/ei/bgn/2823.htm]. (accessed 18 March 2010)

5. Wikepedia: North Kivu. [http://en.wikipedia.org/wiki/North Kivu]. (accessed 18 March 2010) 
6. International A: Amnesty International Report 2009 - DR Congo. 2009 [http://thereport.amnesty.org/en/regions/africa/democratic-republiccongo]. (accessed 18 March 2010)

7. Coghlan B, Ngoy P, Mulumba F, Hardy C, Bemo VN, Stewart T, et al: Update on mortality in the Democratic Republic of Congo: results from a third nationwide survey. Disaster Med Public Health Prep 2009, 3:88-96.

8. Van Herp M, Parqué V, Rackley E, Ford N: Mortality, violence, and lack of access to health care in the Democratic Republic of Congo. Disasters 2003, 27(2):141-153.

9. Ivers LC, Garfein ES, Augustin J, Raymonville M, Yang AT, Sugarbaker DS, Farmer PE: Increasing access to surgical services for the poor in rural Haiti: surgery as a public good for public health. World J Surg 2008, 32:537-542.

10. Ozgediz D, Galukande M, Mabweijano J, Kijjambu S, Mijumbi C, Dubowitz $\mathrm{G}$, et al:: The neglect of the global surgical workforce: experience and evidence from Uganda. World J Surg 2008, 32:1208-1215.

11. Bergström $\mathrm{S}$ : Enhancing human resources for maternal survival:task shifting from physicians to non-physicians. 2008 [http:// www.countdown $2015 \mathrm{mnch} .0 \mathrm{rg} / \mathrm{documents} /$ presentations/20080418bergstrom.pdf]. (accessed 18 March 2010)

12. Chilopora G, Pereira C, Kamwendo F, Chimbiri A, Malunga E, Bergstrom S: Postoperative outcome of caesarean sections and other major emergency obstetric surgery by clinical officers and medical officers in Malawi. Hum Resour Health 2007, 5:17.

13. Pereira C, Cumbi A, Malalane R, Vaz F, McCord C, Bacci A, Bergstrom S: Meeting the need for emergency obstetric care in Mozambique: work performance and histories of medical doctors and assistant medical officers trained for surgery. Bjog 2007, 114:1530-1533.

14. Sani R, Nameoua B, Yahaya A, Hassane I, Adamou R, Hsia RY, et al.: The impact of launching surgery at the district level in Niger. World J Surg 2009, 33:2063-2068

15. Mkandawire N, Ngulube C, Lavy C: Orthopaedic clinical officer program in Malawi: a model for providing orthopaedic care. Clin Orthop Relat Res 2008, 466:2385-2391.

16. Chu K, Rosseel P, Gielis P, Ford N: Surgical task shifting in Sub-Saharan Africa. PLoS Med 2009, 6(5):1-4.

17. Rosseel P, Trelles M, Guilavogui S, Ford N, Chu K: Ten Years of Experience Training Non-Physician Anesthesia Providers in Haiti. World J Surg 2009 2010, 34(3):453-8

18. Ford N, Mills E, Zachariah R, Upshur R: Ethics of research in conflict settings. Conflict \& Health 2009, 3(1):7

doi: 10.1186/1752-1505-4-6

Cite this article as: Chu et al., Surgical care for the direct and indirect victims of violence in the eastern Democratic Republic of Congo Conflict and Health 2010, 4:6

Submit your next manuscript to BioMed Centra and take full advantage of:

- Convenient online submission

- Thorough peer review

- No space constraints or color figure charges

- Immediate publication on acceptance

- Inclusion in PubMed, CAS, Scopus and Google Scholar

- Research which is freely available for redistribution

Submit your manuscript at www.biomedcentral.com/submit
C Biomed Central 